\title{
Perancangan Antena Mikrostrip Segiempat Peripheral Slit untuk Aplikasi 2,4Ghz dengan Metode Pencatuan Proximity Coupled
}

\author{
Rico Bernando Putra ${ }^{1 *}$, Syah Alam², Indra Surjati ${ }^{1}$ \\ ${ }^{1}$ Program Studi Magister Teknik Elektro, Fakultas Teknolodi Industri, Universitas Trisakti \\ ${ }^{2}$ Program Studi Teknik Elektro, Fakultas Teknik, Universitas 17 Agustus 1945 Jakarta \\ ${ }^{*}$ Corresponding author, e-mail: ricobernando25@gmail.com
}

\begin{abstract}
Abstrak - Antena mikrostrip saat ini merupakan salah satu antenna yang sangat pesat perkembangannya dalam sistem telekomunikasi. Antena mikrostrip telah banyak digunakan karena memiliki banyak keuntungan seperti bentuknya yang ringkas, praktis dan mudah untuk mengatur polarisasinya, sehingga banyak diaplikasikan pada peralatan-peralatan telekomunikasi modern saat ini. Pada tulisan ini, dirancang sebuah antena mikrostrip patch segiempat yang bekerja pada frekuensi $2,4 \mathrm{GHz}$ untuk aplikasi Wireless Fidelity (Wi-Fi). Dalam teknik pencatuannya digunakan pencatuan proximity coupled yang bertujuan untuk meningkatkan bandwidth dan menghasilkan return loss $\leq-10 \mathrm{~dB}$ dan VSWR $\leq 2$. Pada perancangan antena ini digunakan beberapa perangkat lunak sebagai bantuan dalam pembuatan antena, diantaranya PCAAD dan AWR Design Environment 2009. Hasil yang diperoleh dari rancang bangun antena ini adalah antena bekerja pada frekuensi $2,244 \mathrm{GHz}-2,537 \mathrm{GHz}$ dengan VSWR pada nilai 1,013 dan Gain pada nilai 5,532 dB dan Return Loss pada nilai $-43,85$ dB.
\end{abstract}

Kata Kunci : Antena Mikrostrip, Rectangular, Proximity, VSWR, Return Loss, Wi-Fi

\begin{abstract}
Microstrip antenna is one of the fastest growing antennas in telecommunication system. Microstrip antenna has been widely used because it has many advantages such as a compact, practical and easy to adjusting polarize, commonly applied to modern telecommunications equipment today. This paper aims to create a rectangular microstrip patch antenna that works at a $2.4 \mathrm{GHz}$ frequency for Wireless Fidelity (Wi-Fi) applications. In the technique of feeder is used the proximity feeders to increase bandwidth and maintain a small return loss. In this antenna design is used some software as aid in making antenna, that is PCAAD and AWR Design Environment 2009. The result obtained from design of this antenna is antenna work at frequency $2,244 \mathrm{GHz}-2,537 \mathrm{GHz}$ with VSWR at value 1.013 and gain at value $5.532 \mathrm{~dB}$ and Return Loss at $-43.85 \mathrm{~dB}$.
\end{abstract}

Keywords : Microstrip Antenna, Rectangular, Proximity, VSWR, Return Loss, Wi-Fi

\section{Pendahuluan}

Perkembangan teknologi informasi saat ini semakin pesat, terutama dalam telekomunikasi tanpa kabel (wireless). Kebutuhan masyarakat akan kecepatan proses transfer data membuat banyak provider telekomunikasi melakukan optimasi jaringan agar dapat memenuhi kebutuhan pelanggan. Disisi user diperlukan sebuah perangkat penerima yang dapat bekerja pada bandwidth lebar agar dapat bekerja untuk beberapa sistem telekomunikasi yang digunakan. Beberapa alokasi frekuensi tersebut adalah DCS berlaku pada pita frekuensi $1.710-1.885 \mathrm{MHz}$, PCS pada pita frekuensi 1.907,5 - 1.912,5 MHz, UMTS pada pita frekuensi $1.920-2.170 \mathrm{MHz}$,
WLAN 2,4 GHz pada pita frekuensi 2.400 2.483,5 MHz, LTE 2,3 GHz [1]. Peraturan Menteri Komunikasi dan Informatika Republik Indonesia Nomor 28/PER/M.KOMINFO/09/2014 menetapkan bahwa rentang frekuensi 2.300 $2.400 \mathrm{MHz}$ digunakan untuk sistem komunikasi pita lebar (broadband) [2].

Sistem komunikasi tanpa kabel membutuhkan suatu alat yang dapat berfungsi sebagai pemancar dan penerima (transmitter dan receiver). Untuk dapat memfasilitasi kebutuhan akan teknologi telekomunikasi yang berkembang saat ini diperlukan perangkat antena yang mampu melakukan penerimaan sinyal di beberapa frekuensi kerja yang berbeda. Untuk menunjang 
kebutuhan tersebut diperlukan suatu antena yang dapat mendukung komunikasi tanpa kabel tersebut. Salah satu jenis antena yang saat ini banyak digunakan untuk komunikasi tanpa kabel adalah antena mikrostrip. Antena mikrostrip memiliki kelebihan, diantaranya bentuk yang kecil, kompak, dan sederhana. Namun, jenis antena ini memiliki beberapa kekurangan, diantaranya gain yang rendah, keterarahan yang kurang baik, efisiensi rendah, rugi-rugi hambatan pada saluran pencatu, dan lebar pita yang sempit [3].

Dalam perkembangan saat ini, perangkat telekomunikasi berkembang dengan ukuran yang semakin kecil dan compact sehingga mudah disimpan dan dioperasikan. Hal ini menunjukkan perlunya sebuah device antena yang memiliki ukuran kecil untuk dapat disisipkan atau dimasukkan ke dalam perangkat telekomunikasi tersebut. Antena mikrostrip sangat cocok untuk dapat diaplikasikan pada perangkat telekomunikasi yang bentuknya kecil, namun kendala yang terjadi adalah efisiensi bandwidth, gain yang kecil, serta keterarahan yang kurang baik sehingga kualitas dan level penerimaan sinyal tidak optimal. Perancangan antena dilakukan agar diperoleh karakteristik antena yang efisien. Penggunaan antena sebagai pemancar dan penerima gelombang radio untuk aplikasi wifi pada frekuensi 2,4 GHz telah banyak diciptakan. Pada penelitian ini dibahas tentang perancangan antena mikrostrip segiempat peripheral slits dengan metode pencatuan proximity coupled untuk mendapatkan optimasi dari parameter bandwitdh yang lebar dengan return loss yang kecil.

Dalam penelitian sebelumnya yang dilakukan oleh [4] diperoleh nilai return loss $-26 \mathrm{~dB}$ dengan bandwidth $8,17 \%$ menggunakan antena mikrostrip rectangular single patch pencatu proximity coupled dengan $x$-slot. Sedangkan pada penelitian antena mikrostrip single patch lainnya pada aplikasi broadband wireless access (BWA) 2,3 $\mathrm{GHz}$ dengan metode pencatuan proximity coupled yang dilakukan oleh [5] berhasil memperoleh nilai return loss -12,2 dB dengan nilai VSWR 1,65 dan bandwidth sebesar $7 \%$.

Teknik peripheral slits sudah banyak diteliti sebelumnya yaitu pada penelitian yang dilakukan oleh [6] mampu menghasilkan antena mikrostrip dengan dimensi menjadi $10 \mathrm{~cm}$ x $10 \mathrm{~cm} \times 10 \mathrm{~cm}$ untuk aplikasi payload satelit nano di frekuensi kerja 436,5 MHz dan pada penelitian oleh [7] dibuktikan bahwa teknik peripheral slits dapat mereduksi dimensi antena sebesar $51 \%$.

Dari beberapa penelitian diatas dapat disimpulkan bahwa teknik pencatu proximity dapat memperbesar bandwidth dan teknik peripheral slits mampu mereduksi dimensi antena. Teknik peripheral slits digunakan untuk dapat memperkecil dimensi dari antena sehingga diperoleh dimensi yang kompak dan mudah diterapkan dalam perangkat telekomunikasi seperti modem. Hal ini yang melatarbelakangi peneliti melakukan penelitian ini.

\section{Metoda Penelitian}

Proses penelitian dilakukan dengan beberapa tahapan untuk memperoleh desain dan dimensi antena mikrostrip. Tahapan awal adalah menentukan substrat beserta spesifikasi yang digunakan dan frekuensi kerja yang diharapkan. Pada penelitian ini substrat yang digunakan adalah FR-4 Epoxy dengan nilai konstanta dielektrik $\varepsilon r=4,3$ dengan ketebalan substrat $\mathrm{h}=1,6 \mathrm{~mm}$ dan loss tangen $=0,0265$ sedangkan frekuensi kerja yang diharapkan dari antena yang dirancang adalah $2.400 \mathrm{MHz}$ untuk aplikasi Wireless Fidelity (Wi-Fi).

Tahapan selanjutnya adalah menentukan saluran catu $50 \mathrm{Ohm}$ yang akan digunakan pada perancangan antena mikrostrip single element. Setelah diperoleh desain awal antena dilanjutkan dengan melakukan perancangan pencatu proximity dengan peripheral slits untuk menghasilkan bandwidth yang lebar dan return loss yang kecil serta dimensi yang ideal.

Setelah itu dilakukan proses iterasi agar diperoleh hasil return loss $\leq-10 \mathrm{~dB}$ dan VSWR $\leq$ 2 sehingga antena dapat bekerja dengan baik pada frekuensi kerja $2.400 \mathrm{MHz}$. Diagram alir (flowchart) perancangan antena mikrostrip peripheral slits dengan metode pencatu proximity coupled dapat dilihat pada Gambar 1 berikut ini.

Penggunaan metode peripheral slit dilakukan untuk mereduksi dimensi antena agar memiliki bentuk yang lebih kompak dan kecil sehingga efisien dan efektif untuk digunakan. Dalam penelitian ini juga antena dikembangkan dengan metode pencatu proximity coupling yaitu metode dengan menempatkan pencatu pada layer yang berbeda sehingga dapat mengkopel elemen peradiasi antena yang ada diatas layer pencatu. Dampak pemberian pencatu proximity adalah dapat meningkatkan bandwidth antena. Pada 
penelitian ini digunakan dua substrat dengan spesifikasi yang sama yaitu FR4 Epoxy dimana elemen pencatu proximity ditempatkan di layer 2 dan elemen peradiasi di layer 1.

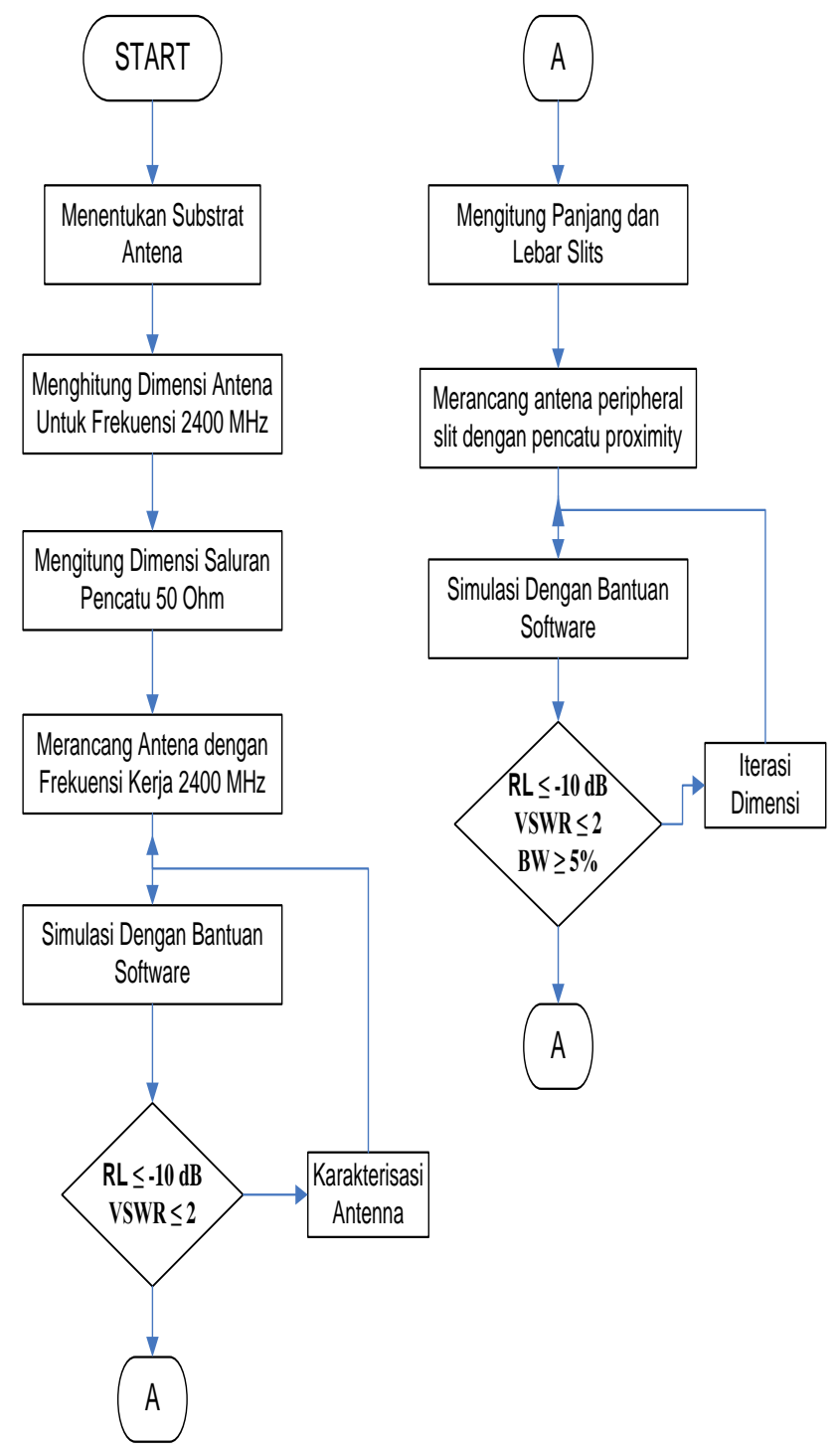

Gambar 1. Diagram alir penelitian

\section{Desain Perancangan Antena}

\subsection{Desain Awal Antena Mikrostrip}

Pada penelitian ini substrat yang akan digunakan adalah FR4 Epoxy. Jenis substrat ini digunakan karena memiliki ketebalan yang cukup kecil, bahan substrat mudah didapatkan, dan memiliki nilai ekonomis bila dibandingkan dengan substrat Taconic TLY-5 tetapi memiliki kerugian, yaitu memiliki konstanta dielektrik yang cukup besar sehingga dapat berpengaruh pada penurunan kinerja antena. Substrat FR4 Epoxy memiliki spesifikasi seperti yang ditunjukkan pada Tabel 1 berikut ini :.

Tabel 1. Spesifikasi substrat FR4 Epoxy

\begin{tabular}{|l|c|}
\hline \multicolumn{1}{|c|}{ Parameters } & Value \\
\hline Konstanta Dielektrik Relatif $\left(\varepsilon_{r}\right)$ & 4,3 \\
Konstanta permeabilitas Relatif $\left(\mu_{r}\right)$ & 1 \\
Dielectric Loss Tangent $(\tan \delta)$ & 0,0265 \\
Ketebalan Substrat $(h)$ & $1,6 \mathrm{~mm}$ \\
Konduktifitas Bahan & $5,8 \times 10^{7} \mathrm{~S} / \mathrm{m}$ \\
\hline
\end{tabular}

Untuk merancang sebuah antena mikrostrip patch segi empat, terlebih dahulu harus diketahui parameter bahan yang digunakan yaitu ketebalan dielektrik (h), konstanta dielektrik (cr), dan dielektrik loss tangent $(\tan \delta)$. Dari nilai tersebut diperoleh dimensi antena mikrostrip (W dan L). Pendekatan yang digunakan untuk mencari panjang dan lebar antena mikrostrip dapat menggunakan persamaan (1) [8, 9].

$$
W=\frac{c}{2 f_{0} \sqrt{\frac{\left(\varepsilon_{r}+1\right)}{2}}}
$$

Dimana :

$$
\begin{aligned}
& W=\text { Lebar konduktor } \\
& \varepsilon_{r}=\text { Konstanta dielektrik } \\
& c=\text { kecepatan cahaya }\left(3 \times 10^{8}\right) \\
& f_{0}=\text { Frekuensi kerja antena }
\end{aligned}
$$

Sedangkan untuk menentukan panjang patch ( $L$ ) diperlukan parameter $\Delta L$ yang merupakan pertambahan panjang dari $L$ akibat adanya fringing effect. Pertambahan panjang dari $L(\Delta L)$ tersebut dapat dicari menggunakan persamaan (2) [8][9].

$$
\frac{\Delta L}{h}=0.412 \frac{\left(\varepsilon_{e}+0.3\right)\left[\frac{W}{h}+0.264\right]}{\left(\varepsilon_{e}-0.258\right)\left[\frac{W}{h}+0.813\right]}
$$

Dimana $h$ merupakan tinggi substrate atau tebal substrate, dan $\varepsilon_{e}$ adalah konstanta permitivitas efektif yang dapat diperoleh dengan menggunakan persamaan (3).

$$
\varepsilon_{e}=\frac{\varepsilon_{r}+1}{2}+\frac{\varepsilon_{r}-1}{2}\left(1+12 \frac{h}{W}\right)^{-\frac{1}{2}}
$$

Panjang patch $(L)$ dapat diperoleh dengan menggunakan Persamaan (4).

$$
L=L_{e f f}-2 \Delta L
$$

Dengan $L_{\text {eff }}$ merupakan panjang patch efektif yang dapat dihitung menggunakan persamaan (5). 


$$
L_{e f f}=\frac{c}{2 f_{0} \sqrt{\varepsilon_{\text {reff }}}}
$$

Hal yang mempengaruhi kerja antena selain lebar dan panjang patch peradiasi adalah lebar saluran pencatu $\left(W_{z}\right)$. Saluran pencatu yang digunakan memiliki impedansi $50 \mathrm{Ohm}$. Lebar saluran pencatu dapat diperoleh dengan menggunakan persamaan (6) dan (7) [10].

$$
\begin{aligned}
& W_{z}=\frac{2 h}{\pi}\left\{B-1-\ln (2 B-1)+\frac{\varepsilon_{r}-1}{2 \varepsilon_{r}}[\ln (B-\right. \\
& \left.\left.1)+0,39 \frac{0,61}{\varepsilon_{r}}\right]\right\}
\end{aligned}
$$

Dimana :

$$
B=\frac{377 \pi}{2 Z_{0} \sqrt{\varepsilon_{r}}}
$$

Setelah melakukan perhitungan berdasarkan persamaan matematis tersebut, maka diperoleh ukuran antena mikrostrip sebagai berikut : lebar patch $(W)$ sebesar $38,37 \mathrm{~mm}$. panjang patch $(L)$ sebesar 29,76 mm. Lebar saluran pencatu yang diberi simbol dengan huruf $\left(W_{z}\right)$ sebesar 3,1 mm. Hasil rancangan satu elemen peradiasi (patch) antena mikrostrip seperti terlihat pada gambar 2 berikut ini.

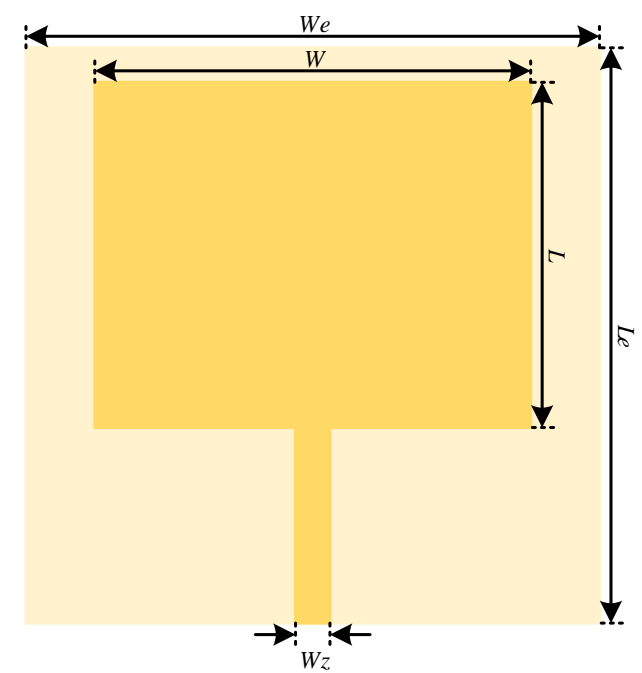

Gambar 2. Desain awal antena satu elemen peradiasi pencatu tidak langsung

Setelah dilakukan simulasi dan dilakukan beberapa kali iterasi dengan perangkat lunak diperoleh nilai terbaik pada saat lebar patch (W) sebesar $37 \mathrm{~mm}$ dan panjang patch (L) sebesar 29 mm dengan ukuran lebar enclosure (W_e) $49 \mathrm{~mm}$ dan panjang enclosure (L_e) $49 \mathrm{~mm}$. Seperti yang terlihat pada gambar 3 dan 4 , diperoleh hasil simulasi dengan nilai Return Loss $-24.55 \mathrm{~dB}$ dan nilai VSWR 1,126. Dapat dilihat juga pada gambar 3, antena bekerja pada frekuensi 2320 $\mathrm{MHz}$ - $2487 \mathrm{MHz}$ sehingga dapat kita hitung besarnya bandwidth dengan persamaan (8) [9].

$$
\begin{aligned}
& B w=f_{u}-f_{l} \\
& B w=2487-2320=167 \mathrm{MHz}
\end{aligned}
$$

Dengan persentase :

$$
\begin{aligned}
B_{p} & =\frac{f_{u}-f_{l}}{f_{0}} \times 100 \% \\
B p & =\frac{2487-2320}{2400} \times 100 \%=6,95 \%
\end{aligned}
$$

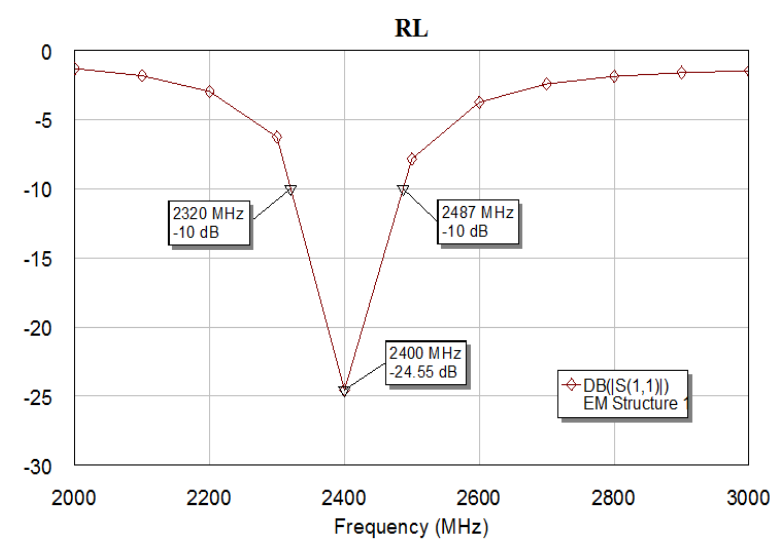

Gambar 3. Grafik simulasi return loss antena satu elemen peradiasi

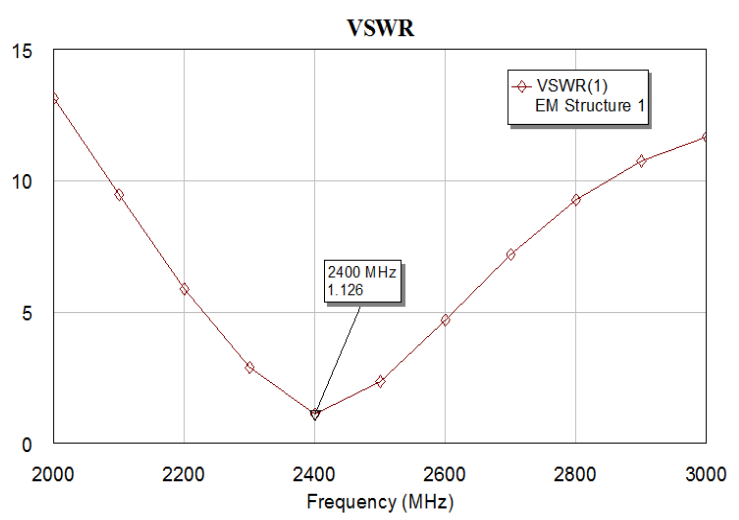

Gambar 4. Grafik simulasi VSWR antena satu elemen peradiasi

Pada Gambar 3 dan 4 dapat dilihat hasil simulasi return loss dan VSWR antena mikrostrip dengan satu elemen peradiasi. Dari hasil simulasi awal diperoleh nilai return loss $-24,55 \mathrm{~dB}$ dan VSWR 1,126 pada frekuensi kerja $2400 \mathrm{MHz}$. 


\subsection{Desain Antena Mikrostrip Peripheral Slit dengan pencatu proximity}

Peripheral slits adalah salah satu teknik miniaturisasi ukuran antena microstrip yang bekerja dengan cara membuat beberapa belahan (slits) pada sisi-sisi patch antena. Penggunaan slits akan menganggu aliran arus di permukaan, memaksa arus untuk berbelok-belok, yang kemudian meningkatkan panjang elektris dari patch. Pada akhirnya, frekuensi operasi akan turun, sedangkan dimensi fisik dari patch tetap. Sampai tahap tertentu, nilai frekuensi dapat direduksi dengan semakin menambah panjang slit. Jumlah slit yang digunakan semakin banyak juga akan dapat mengurangi frekuensi kerja. Dengan menggunakan beberapa buah slit, arus di permukaan akan mengalir di sekeliling slits.

Hasilnya adalah (a) memperpanjang ukuran elektris dari patch dan (b) timbulnya arus yang normal searah dengan arus eksitasi.

Teknik peripheral slits ini memiliki ukuran lebar slits $\left(w_{s}\right)$ dan panjang slits $\left(l_{s}\right)$ yang sama antara satu dengan yang lainnya. Pada umumnya untuk lebar slits $\left(w_{s}\right)$ berkisar antara $1 \mathrm{~mm}-6 \mathrm{~mm}$, sedangkan untuk panjang slits $\left(l_{s}\right)$ dapat menggunakan Persamaan (9) [11].

$$
l_{s}=0,4 L
$$

Setelah dilakukan perhitungan dengan persamaan (9) diperoleh desain antena peripheral slits dengan 4 slits seperti yang terlihat pada Gambar 5 di bawah ini. Dalam penelitian ini digunakan pencatu proximity feed line untuk memperlebar nilai bandwidth antena. Pencatu proximity di tempatkan pada layer yang berbeda dengan spesifikasi yang sama dengan elemen peradiasi dan berada di bawah patch antena elemen peradiasi yang berbentuk peripheral slits. Struktur dari dimensi antena dengan pencatu proximity dapat dilihat pada tampilan 3 dimensi di Gambar 6.

Pada Gambar 6 dapat dilihat bahwa pencatu proximity berada pada layer $1\left(\varepsilon_{\mathrm{r}} 1\right)$ dan elemen peradiasi layer $2\left(\varepsilon_{\mathrm{r}} 2\right)$ dengan jenis substrat yang sama yaitu FR4 Epoxy. Pencatu proximity nantinya akan menkopel antena yang ada berada di layer diatasnya sehingga dapat menghasilkan bandwidth yang lebih lebar daripada menggunakan pencatu microstrip line.

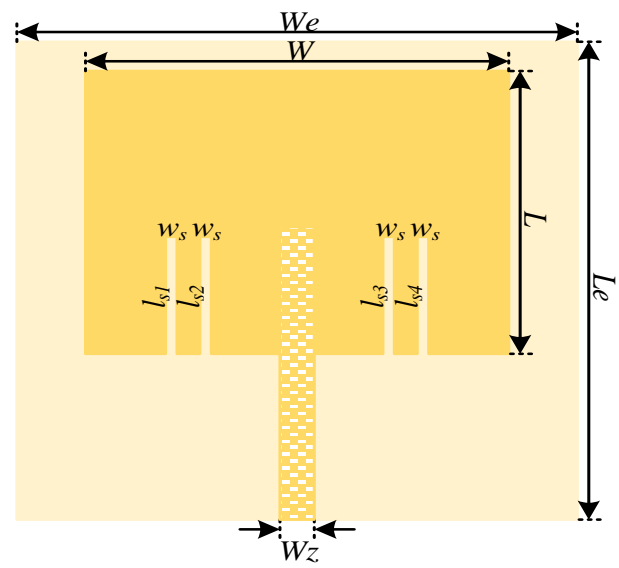

Gambar 5. Desain antena mikrostrip peripheral slit dengan pencatu proximity

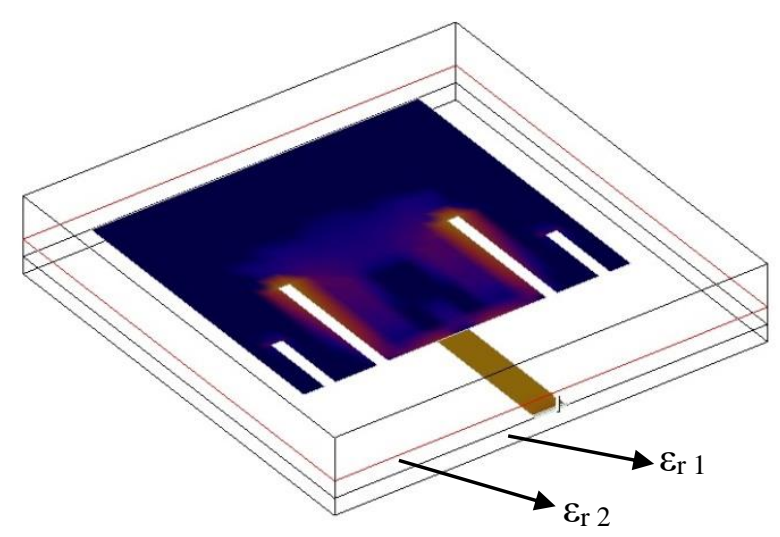

Gambar 6. Desain antena mikrostrip 3 dimensi dengan pencatu proximity

\section{Hasil dan Pembahasan}

Untuk memperoleh nilai simulasi terbaik maka dilakukan proses iterasi dengan melakukan perubahan pada panjang slits $\left(l_{s}\right)$ dan luas $\left(W_{e} \times L_{e}\right)$ enclosure. Proses iterasi ini diharapkan agar antena bekerja pada frekuensi yang telah ditentukan dan memiliki parameter return loss $\leq$ $10 \mathrm{~dB}$ dan VSWR $\leq 2$ [12]. Tabel 2 menunjukan hasil terbaik dari beberapa iterasi yang dilakukan dan dapat dilihat juga hasil simulasi pada gambar 7 dan 8 . 
Tabel 2. Dimensi iterasi antena mikrostrip

\begin{tabular}{|c|c|c|c|c|c|c|c|}
\hline Iterasi & $\boldsymbol{w}_{\boldsymbol{s}}$ & $\boldsymbol{l}_{\boldsymbol{s} \mathbf{1}}$ & $\boldsymbol{l}_{\boldsymbol{s} \mathbf{2}}$ & $\boldsymbol{l}_{\boldsymbol{s} \mathbf{3}}$ & $\boldsymbol{l}_{\boldsymbol{s 4}}$ & $\mathbf{R L}$ & \multirow{2}{*}{ VSWR } \\
\cline { 1 - 6 } $\mathbf{N}$ & $\mathbf{( m \mathbf { m } )}$ & $\mathbf{( m \mathbf { m } )}$ & $\mathbf{( m \mathbf { m } )}$ & $\mathbf{( m m )}$ & $\mathbf{( m m )}$ & $\mathbf{( d B )}$ & \\
\hline ke-1 & 1 & 4 & 12 & 12 & 4 & $-15,47$ & 1,046 \\
ke-2 & 1 & 12 & 12 & 12 & 12 & $-25,35$ & 1,115 \\
ke-3 & 1 & 7 & 13 & 13 & 7 & $-43,85$ & 1,013 \\
\hline
\end{tabular}

Dari tabel 2 dapat dilihat bahwa parameter yang di iterasi adalah $w s, I_{s 1}, I_{s 2}, I_{s 3}$ dan $I_{s 4}$ untuk memperoleh hasil simulasi terbaik.

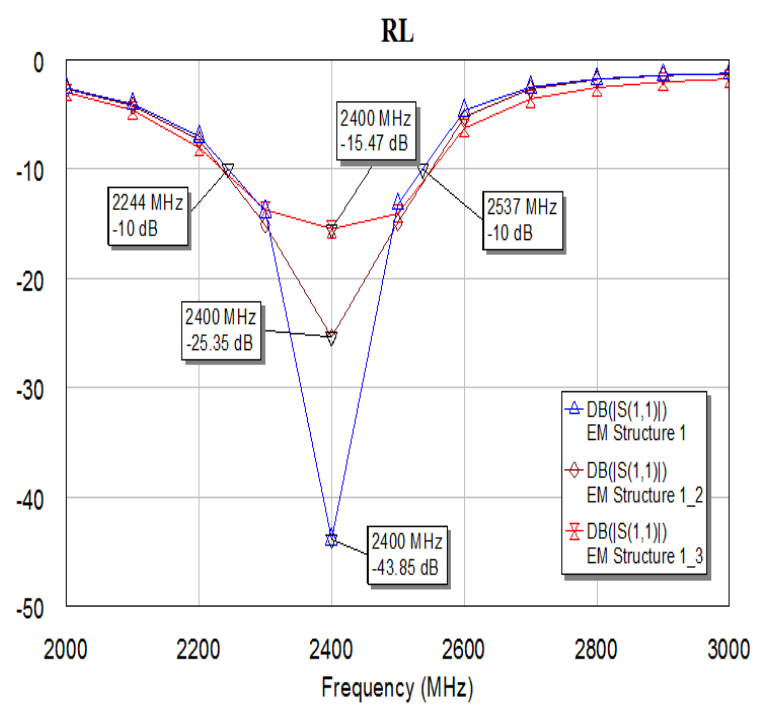

Gambar 7. Grafik simulasi return loss antena hasil iterasi

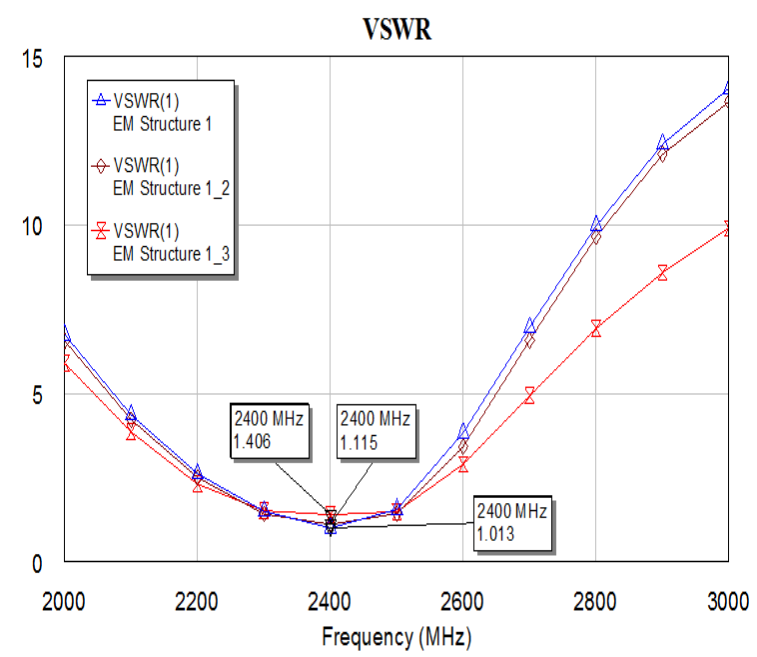

Gambar 8. Grafik simulasi VSWR antena hasil iterasi

Optimasi dilakukan dengan cara melakukan beberapa kali iterasi untuk mendapatkan hasil simulasi yang terbaik, dapat kita lihat pada Tabel 2 bahwa hasil terbaik diperoleh pada iterasi 3 dengan nilai return loss $-43,85 \mathrm{~dB}$ dan VSWR 1,013. Pada Gambar 6 dapat dilihat juga hasil simulasi menunjukan bandwidth yang diperoleh pada iterasi 3 tersebut sebesar $293 \mathrm{MHz}$. Penambahan slits ini juga berhasil mereduksi ukuran dari enclosure. Tabel 4 menunjukan perbandingan hasil simulasi desain antena awal dengan desain antena peripheral slits dengan teknik pencatuan proximity.

Tabel 3. Dimensi iterasi antena mikrostrip

\begin{tabular}{|c|c|c|c|c|c|c|}
\hline Desain & $\begin{array}{c}\text { Luas } \\
\text { enclosure } \\
(\mathrm{mm})\end{array}$ & $\begin{array}{c}\text { Luas } \\
\text { patch } \\
\left(\mathrm{mm}^{2}\right)\end{array}$ & $\begin{array}{c}\text { Return } \\
\text { Loss } \\
(\mathrm{dB})\end{array}$ & VSWR & $\begin{array}{c}\text { Gain } \\
(\mathrm{dB})\end{array}$ & $\begin{array}{c}\text { BW } \\
(\mathrm{MHz})\end{array}$ \\
\hline Awal & $49 \times 49$ & $37 \times 29$ & $-24,55$ & 1,126 & 5,724 & 167 \\
$\begin{array}{c}\text { Peripheral } \\
\text { Slit dengan } \\
\text { proximity }\end{array}$ & $41 \times 41$ & $31 \times 28$ & $-43,85$ & 1,013 & 5,532 & 293 \\
\hline
\end{tabular}

Dari Tabel 3 dapat dilihat bahwa dengan teknik peripheral slits mampu mereduksi dimensi antena sebesar $30 \%$ sehingga didapat dimensi antena yang optimal, yaitu dengan ukuran enclosure 41 x $41 \mathrm{~mm}$ dan ukuran patch 31 x 28 $\mathrm{mm}$. Bandwidth yang sebelumnya pada desain awal sebesar $167 \mathrm{MHz}$ dapat diperlebar menjadi $293 \mathrm{MHz}$ atau meningkat menjadi $12 \%$. Namun gain menurun sebesar 3\%, hal ini dikarenakan konsekuensi dari penerapan peripheral slits ini adalah berdampak pada penurunan gain.

\section{Kesimpulan}

Dari hasil simulasi yang dilakukan bahwa antena yang dirancang dapat bekerja pada frekuensi $2400 \mathrm{MHz}$ dengan bandwidth sebesar $293 \mathrm{MHz}$ dilihat dari nilai Return Loss yaitu 43,85 dB dan VSWR 1,013. Teknik pencatuan proximity berhasil memperlebar bandwidth dilihat dari peningkatan bandwidth yang semula 176 $\mathrm{MHz}$ menjadi $293 \mathrm{MHz}$ atau meningkat sebesar $12 \%$. Penerapan peripheral slits terbukti dapat mereduksi dimensi antena sebesar $30 \%$, sehingga diperoleh desain akhir yang optimal dengan ukuran enclosure 41 x $41 \mathrm{~mm}$ dan ukuran patch $31 \times 28 \mathrm{~mm}$. Konsekuensi dari peripheral slits ini adalah terjadinya penurunan gain dilihat dari gain desain awal sebesar 5,724 dB menjadi 5,532 dB atau menurun sebesar 3\% sehingga pada penerapan peripheral slits ini dibutuhkan pertimbangan dalam penentuan dimensi terhadap gain yang dibutuhkan. 


\section{DAFTAR PUSTAKA}

[1] Postel, Ditjen. "Penataan Frekuensi Radio Layanan Akses Pita Lebar Berbasis Nirkabel." (2006).

[2] Kementerian Komunikasi dan Informatika Republik Indonesia. Permenkominfo No.28/PER/M.KOMINFO/09/2014 tentang "Penetapan Pita Frekuensi Radio Untuk Keperluan Layanan Pita Lebar Nirkabel (Wireless Broadcast) Pada Pita Frekuensi 2.3 GHz", Jakarta, (2010).

[3] Alam, Syah. "The Design of Triangular Microstrip Antenna for Wimax Application at $2.300 \mathrm{MHz}$ Frequency." Teknik dan Ilmu Komputer 4.(15) (2016).

[4] Sastry, IVS Rama, and K. Jaya Sankar. "Proximity coupled Rectangular Microstrip Antenna with X-slot for WLAN Application." Global Journal of Research In Engineering. (2014).

[5] Tarigan, C. E. A., \& Rambe, A. H.. Rancang Bangun Antena Mikrostrip Slot Rectangular Dual-Band (2, 3 GHz Dan 3, 3 $\mathrm{GHz}$ ) Dengan Pencatuan Proximity Coupled. Singuda ENSIKOM, 11(31), 112117. (2015)

[6] Sujadi, A., Setijadi, E., \& Hendrantoro, G. Desain Antena Microstrip dengan Tapered Peripheral Slits untuk Payload Satelit Nano pada Frekuensi 436, 5 MHz. Jurnal Teknik ITS, 1(1), A25-A30. (2012).

[7] Liu, C., Xiao, S., Guo, Y. X., Bai, Y. Y., Tang, M. C., \& Wang, B. Z. Compact circularly-polarised microstrip antenna with symmetric-slit. Electronics letters, 48(4), 195-196. (2012).

[8] Garg, R. Microstrip antenna design handbook. Artech house. (2001)

[9] Surjati, I.. Antena Mikrostrip: Konsep dan Aplikasinya. Penerbit Universitas Trisakti, Jakarta. (2010)

[10] Hermansyah, M. R. Rancang Bangun Antena Microstrip Patch Segi Empat Untuk Aplikasi Wireless-Lan. (2010).
[11] Notis, D. T., Liakou, P. C., \& Chrissoulidis, D. P. Dual polarized microstrip patch antenna, reduced in size by use of peripheral slits. In Microwave Conference, 2004. 34th European (Vol. 1, pp. 125-128). IEEE. (2004, October).

[12] Amir, M. A. Rancang Bangun Antena Mikrostrip Biquad Ganda untuk Aplikasi Wi-Fi. JURNAL NASIONAL TEKNIK ELEKTRO, 3(1). (2014).

\section{Biodata Penulis}

N. Rico Bernando Putra, menamatkan pendidikan S1 di Jurusan Teknik Elektro Universitas Bengkulu pada tahun 2012, dan saat ini sedang meneruskan ke jenjang pendidikan S2 diselesaikan di Magister Teknik Elektrodi Universitas Trisakti dengan konsentrasi bidang telekomunikasi.

Syah Alam, menamatkan pendidikan S1 di Jurusan Pendidikan Teknik Elektro Universitas Pendidikan Indonesia pada tahun 2004, dan jenjang pendidikan S2 diselesaikan di Magister Teknik Elektro Universitas Trisakti dengan konsentrasi bidang teknik telekomunikasi pada tahun 2010. Saat ini Penulis terdaftar sebagai dosen di Program Studi Teknik Elektro Universitas 17 Agustus 1945 Jakarta. Minat penelitian Penulis adalah antena mikrostrip dan wireless

Indra Surjati, menamatkan pendidikan S1 di Jurusan Teknik Elektro Universitas Trisakti pada tahun 1985, dan jenjang pendidikan S2 diselesaikan di Magister Teknik Elektro Universitas Trisakti dengan konsentrasi bidang teknik telekomunikasi pada tahun 1996. Setelah itu penulis menyelesaikan pendidikan doktoral S3 di Pasca Sarjana Universitas Indonesia pada tahun 2004. Saat ini Penulis terdaftar sebagai dosen dan guru besar di Jurusan Teknik Elektro Universitas Trisakti. Minat penelitian Penulis adalah antena mikrostrip dan wireless. 